\title{
Effects of dark or of red, blue or white light on germination of subterranean clover seeds
}

\author{
Alexandra Costa ${ }^{1,2 \ddagger}$, Alexandra Soveral Dias ${ }^{1 \ddagger}$, Maria Gertrudes Grenho1, Luís Silva Dias ${ }^{1 *}$ \\ ${ }^{1}$ Departamento de Biologia, Universidade de Évora, Évora, Portugal, ${ }^{2}$ Instituto de Ciências Agrárias e Ambientais Mediterrânicas, \\ Universidade de Évora, Évora, Portugal \\ These authors contributed equally to this work.
}

\section{A B S TR A C T}

Dry or imbibed seeds of the negatively photoblastic burr burying subterranean clover cv. 'Seaton Park' were treated with dark or with red, blue or white light to evaluate the effects of light on seed germination. Dry seeds treated with constant white light, red light or blue light during 8 days and subsequently incubated in dark had final germination and duration of germination reduced, and the distribution of germination changed from highly asymmetric to symmetric respectively. Imbibing seeds incubated under constant blue or white light had final germination strongly reduced seven days after sowing $(7.3 \%$ and $50.1 \%$ of the germination under dark) with significant differences between them. After transferral to dark, true complete recovery of germination of seeds treated with white light was observed 19 days after sowing, but only partial recovery in seeds treated with blue light. Results of dry and imbibed seeds are consistent with no activity of phytochromes, as expected in negatively photoblastic seeds. Results of dry seeds are seemingly contradictory because total germination data imply the inactivity of red and blue light photoreceptors, the opposite being implied by duration and shape of germination. A tentative hypothetical solution for the contradiction is presented. Results of imbibed seeds are fully consistent with cryptochromes but not with phototropins mediation of responses to light of seed germination in 'Seaton Park'. The ecological and adaptive significance of such responses are discussed in the framework of light attenuation in soil and the requirement and ability of subterranean clover 'Seaton Park' to bury seeds.

Keywords: Cryptochromes; Dark; Germination; Light; Subterranean clover

\section{INTRODUCTION}

Seed germination is a critical process for plants that once started is irreversible and commits the embryo to only two possible outcomes, death or growth (Fenner and Thompson, 2005). Simultaneously seed germination and the subsequent period that ends with the establishment of an independent juvenile plant constitutes one of the most vulnerable phases of plants' life cycle (Kitajima and Fenner, 2000). Therefore timing of germination is critical so that seed germination, radicle penetration in soil and seedling emergence from soil might happen in the moment most favourable for plant survival. A number of factors are known to control the initiation of seed germination. Light is one of them, and in a recent review major emphasis is put on phytochrome role and on positively photoblastic seeds (Pons, 2014). This is not surprising given the predominance of positively photoblastic species requiring light for germination compared to negatively photoblastic species requiring darkness (Górski et al., 1977, 1978; Milberg et al., 2000).

However and despite being relatively infrequent, negative photoblasty is still found in a number of species, cultivated or not, subterranean clover being among the former. Subterranean clover (Trifolium subterraneum) is an annual herbaceous legume able to withstand the hot, dry summer characteristic of Mediterranean-type environments. Simultaneously it enriches soil with biologically fixed nitrogen which is viewed as the second most fundamentally important biological process after photosynthesis (Howieson et al., 2008; Nichols et al., 2012). Two distinctive characteristics make subterranean clover a particularly successful pasture species. The first is its high tolerance to regular close grazing, particularly by sheep, mostly because of subterranean clover's prostrate growth;

\footnotetext{
${ }^{*}$ Corresponding author:

Luís Silva Dias, Departamento de Biologia, Universidade de Évora, Ap. 94, 7002-554 Évora, Portugal. Tel.: +351-266-760-881,

Fax: +351-266-760-914. E-mail: Isdias@uevora.pt
}

Received: 30 July 2016; $\quad$ Revised: 07 November 2016;

Accepted: 08 November 2016;

Published Online: 18 November 2016 
the second its ability to bury its burrs thus providing seeds with an escape, at least partial, to stock predation (Nichols et al., 2012). However, burial ability varies widely within and among subterranean clover subspecies. The higher ability to bury burrs is found in subspecies subterranean the lower in subspecies bracbycalycinum (Francis et al., 1972). Therefore, cultivars of the former subspecies, especially those with a very high ability to bury burrs can provide a very good model to study germination responses to various light conditions in negative photoblastic species like subterranean clover, because high burying ability and high dependence of germination from dark can be expected to be highly correlated.

We selected 'Seaton Park' among cultivars of subspecies subterraneum to investigate responses of germination to dark or to red, blue or white light not only because of its high burial ability but also because of the intermediate level of hardseededness at maturation it presents (Taylor, 1981; Smetham, 1999; Nichols et al., 2013). Thus, in all likelihood seed germination of 'Seaton Park' will be more responsive to light cues and less to seed coat permeability. Adding to these features, 'Seaton Park' has very low levels of formononetin, an oestrogenic isoflavone that is the main cause of cystic glandular hyperplasia in sheep, commonly named 'clover disease' (Nichols et al., 2013).

The present study was conducted to investigate 1) the effects on germination of light treatments imposed to dry seeds before water is available and seeds can imbibe, hereafter referred to as dry seeds experiment, and 2) the effects on germination of light treatments imposed to imbibing seeds as well as the response of non-germinated seeds to subsequent transferral to dark, hereafter referred to as imbibed seeds experiment.

\section{MATERIALS AND METHODS}

\section{Plant material}

Seeds of Trifolium subterraneum L. cv. 'Seaton Park' (Fabaceae) were provided by a specialized seed producer (Fertiprado Lda., Portugal), and were stored in dark in closed paper bags under room conditions before being used. Seeds of this cultivar are round to slightly ovoid with little or no evidence of heteromorphy, either in size, shape or colour. Colour is anthracite (RGB decimal colour code mainly 43, 41, 20; HEX code \#2B2914).

\section{Water content of seeds}

Ten samples of 25 seeds each were randomly selected, weighted to the nearest $\mathrm{mg}$ with a scale Mettler Toledo, dried for $72 \mathrm{~h}$ at $60^{\circ} \mathrm{C}$ in a Memmert drying oven, allowed to cool in water-free atmosphere, and weighted again. Water content per seed was determined as the difference between fresh and oven dried mass in percentage of fresh mass and ranged from $5.03 \%$ and $6.32 \%$ with a mean $( \pm$ SE) of $5.78 \pm 0.16 \%$ and a median of $5.97 \%$.

\section{Biometry of seeds}

One hundred seeds were randomly selected and their length, width and thickness individually determined using a digital calliper Comecta S.A. or a stereomicroscope Leica GZ4 equipped with an eyepiece micrometre Leitz Periplan $10 \times 18 \mathrm{M}$ under $10 \times 3$ total magnification. Individual seed mass was determined to the nearest $0.1 \mathrm{mg}$ with a scale Precise XR 2055M-DR and ranged from $2.7 \mathrm{mg}$ to $13.1 \mathrm{mg}$ with a mean $( \pm \mathrm{SE})$ of $5.9 \pm 0.2 \mathrm{mg}$ and a median of $5.7 \mathrm{mg}$. Seed volume was determined from length, width and thickness measurements (Casco and Dias, 2008). Volume ranged from $8.467 \mathrm{~mm}^{3}(3.50 \times 3.50 \times 1.32 \mathrm{~mm})$ to $39.888 \mathrm{~mm}^{3}(5.74 \times 5.53 \times 2.40 \mathrm{~mm})$ with a mean $( \pm \mathrm{SE})$ of $19.268 \pm 0.631 \mathrm{~mm}^{3}$ and a median of $19.132 \mathrm{~mm}^{3}$. Seed sphericity was determined with data scaled to length as unity by dividing length, width and thickness by length (Bakker et al., 1996). Sphericity ranged from 0.056 to 0.114 , with a mean $( \pm \mathrm{SE})$ of $0.079 \pm 0.001$ and a median of 0.078 . For perspective, perfect sphericity equals zero while the elongated caryopses of Digitaria sanguinalis range from 0.115 to 0.140 (Casco and Dias, 2008). Seed density was derived from seed mass and volume and is low ranging from 0.237 to 0.424 with a mean $( \pm \mathrm{SE})$ of $0.313 \pm 0.004$ and a median of 0.310 .

\section{Characterisation of light treatments}

Red and blue light treatments were carried in climatic chambers Fitoclima 1200 (Aralab, Lda., Portugal) set to constant $20{ }^{\circ} \mathrm{C}$ equipped with $5 \times 10$ grids of Philips LED lamps. Red light was provided by GreenPower LED Research Module Deep Red; PPF was $\sim 342 \mu \mathrm{mol} \mathrm{m}^{-2} \mathrm{~s}^{-1}, 100 \%$ in the range $600-700 \mathrm{~nm}$. Blue light was provided by GreenPower LED Research Module Blue; PPF was $\sim 344 \mu \mathrm{mol} \mathrm{m}^{-2}, 100 \%$ in the range 400-500 nm. High intensity white light was provided by 8 Osram L18W/480 fluorescent tubes also installed in a climatic chamber Fitoclima 1200 set to constant $20{ }^{\circ} \mathrm{C}$; PPF was $\sim 356 \mu \mathrm{mol} \mathrm{m}^{-2} \mathrm{~s}^{-1}, 21.1 \%, 47.3 \%$ and $31.7 \%$ in the ranges $400-500 \mathrm{~nm}, 500-600 \mathrm{~nm}$ and $600-700 \mathrm{~nm}$ respectively (Fig. 1). Light parameters were determined with a SKP 200 meter (Skye Instruments Ltd.) and an USB2000 spectrometer (Ocean Optics, Inc.).

\section{Effects of light treatments on dry seeds}

All 16 samples of 25 randomly selected subterranean clover seeds used in the dry seeds experiment were separately weighted to the nearest mg with a scale Kern PLJ 600-3 NM. 


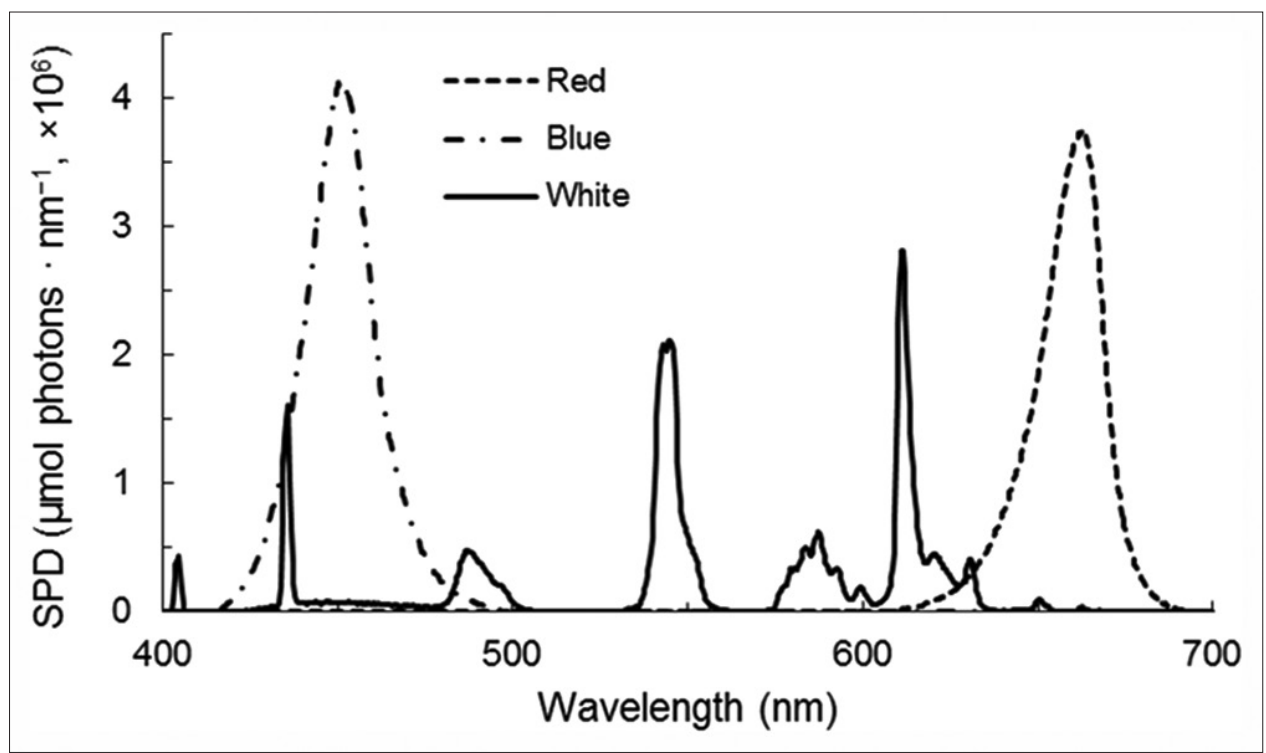

Fig 1. Spectral photon distribution (SPD) of red, blue or white light treatments.

Four samples per treatment were kept in constant dark or under constant red, blue or white light during 8 days. Dark-treated seeds were kept in a closed opaque plastic box in a climatic chamber Fitoclima 1200. Red, blue, and white light treatments were performed as described above.

After 8 days four $9 \mathrm{~cm}$ plastic Petri dishes per treatment were fitted with Whatman No. 1 filter paper, sown with 25 seeds each and wetted with $3.5 \mathrm{~mL}$ of distilled water. Sowing and wetting was done under natural white dim light. All Petri dishes were placed inside a closed opaque plastic box and seeds incubated under constant dark during 16 days in a chamber Fitoclima 1200 set to $20^{\circ} \mathrm{C}$. Distance from the cover of the opaque box to lamps was $\sim 42 \mathrm{~cm}$. After the onset of the experiment further additions of distilled water were done whenever deemed necessary.

Seeds were considered to have germinated when the embryo, normally the root, protruded the seed coat and were checked for those who completed germination, which were discarded, twice a day during the first 4 days, and once a day afterwards. Seeds were outside climatic chambers to check germination under dim white, dim red, dim blue or white light from less than one minute to $10 \mathrm{~min}$, the latter in dark treatments in the first and second days after sowing when the majority of seeds germinated. Mean time outside climatic chambers was $3.2 \pm 0.3 \mathrm{~min}$.; median was $3.0 \mathrm{~min}$. Temperature inside the closed plastic box containing Petri dishes was $\sim 22{ }^{\circ} \mathrm{C}$. An exploratory experiment showed that brief exposures to dim white light did not affect germination of 'Seaton Park' seeds incubated under dark (data not shown). Therefore we always examined seeds under such conditions. In the end of the bioassay non-germinated seeds were examined for death and hardness by applying pressure with tweezers (Roberts and Ricketts, 1979).

\section{Effects of light treatments on imbibed seeds}

All 16 samples of 25 randomly selected subterranean clover seeds used in the imbibed seeds experiment were separately weighted to the nearest $\mathrm{mg}$ with a scale Kern PLJ 600-3 NM.

Four $9 \mathrm{~cm}$ plastic Petri dishes per light treatment were fitted with Whatman No. 1 filter paper, sown with 25 seeds each and wetted with $3.5 \mathrm{~mL}$ of distilled water. Sowing and wetting was done under natural white dim light and seeds were incubated under constant light in climatic chambers Fitoclima 1200 set to $20{ }^{\circ} \mathrm{C}$ equipped with red, blue or white light as described above. Dark-treated seeds were placed inside a closed opaque plastic box and incubated in the same temperature conditions. Distance from the cover of Petri dishes to LEDs or fluorescent tubes was $\sim 40 \mathrm{~cm}$, while distance from the cover of the opaque box to lamps was $\sim 42 \mathrm{~cm}$. After the onset of the experiment further additions of distilled water were done whenever deemed necessary.

Seeds were considered to have germinated when the embryo, normally the root, protruded the seed coat and were checked for those who completed germination, which were discarded, twice a day during the first 3 days, and once a day afterwards.

To evaluate the recovery of germination the replicates of red, blue and white light treatments were divided 7 days after sowing (DAS) in two groups as described elsewhere (Dias et al., 2015). One group included replicates with 
the highest and lowest germination and the other the two replicates with intermediate values. Seeds of the first group hereafter referred to as recovery group or recovery seeds were transferred to constant dark conditions whereas seeds of the second group hereafter referred to as continuance group or continuance seeds were kept in the same light conditions in which they were from the beginning of the experiment. Assignment of seeds to the recovery and continuance groups was random. Thereafter seeds were checked for those who completed germination, which were discarded, for an additional 12 day period.

During the entire experiment checking of germinated seeds was done under dim white, red or blue light or under direct white light according to the treatment conditions of seeds. Seeds were outside climatic chambers under dim white, dim red, dim blue or white light to check germination from less than one minute to $15 \mathrm{~min}$., the latter in the first DAS in red light treatment. Mean time outside climatic chambers was $3.1 \pm 0.3 \mathrm{~min}$., median was $2.0 \mathrm{~min}$. Temperature inside the closed plastic box containing Petri dishes in the dark treatment, including recovery was $\sim 22{ }^{\circ} \mathrm{C}$. In the end of the bioassay non-germinated seeds were also examined for death and hardness by applying pressure with tweezers (Roberts and Ricketts, 1979).

\section{Statistical analyses}

Germination was sometimes recorded in seemingly not imbibed seeds, also resistant to pressure by tweezers, undistinguishable in those aspects to hard seeds. Thus final germination was expressed as percentage of the total number of seeds sown.

Lag, rate, and shape of germination were obtained from the three-term Weibull function (Weibull, 1951) fitted by least squares nonlinear regression without replication using the Marquardt method (Marquardt, 1963). The three-term Weibull function can be expressed as:

$G_{\mathrm{T}}=1-\exp \left\{-\left[(\mathrm{T}-\delta / k]^{c}\right\}\right.$

where $G_{\mathrm{T}}$ is the cumulative germination at time $\mathrm{T}$ in proportion of total germination registered at the end of the bioassay; l(lag of germination) is a location parameter that estimates the latest time at which germination is strictly zero, which in practice represents the time necessary for the first seed to complete germination; $k$ (rate of germination) is a scale parameter estimating the rate of germination completion over time with $l+k$ estimating the time necessary for the completion of $63 \%$ of cumulative germination; $c$ is a dimensionless shape parameter estimating the symmetry of the distribution of germination over time, with $3.25 \leq \leq \leq 3.61$ showing symmetry a representing a good approximation to the normal distribution, $c<3.25$ positive asymmetry, c>3.61 negative asymmetry (Dubey, 1967; Bonner and Dell, 1976). Fitted equations were only accepted after a consistency check of parameter estimates and germination predictions against the original data (Dias, 2001). Duration of germination $\left(D_{100}\right)$, the number of days necessary to attain total germination minus the number of days necessary for germination to start ( $($ ) was deduced from fitted equations.

The relationship between seed mass and germination, including Weibull parameters, was investigated using data of the two experiments pooled together by least squares linear regression without replication with forward stepwise selection. Candidate models included up to the third power of seed mass, with an experiment-wise type I error rate of 0.05 for coefficients calculated using Dunn-Šidak method (Ury, 1976).

Continuance (CG) and recovery (RG) of germination were determined as a percentage using

$C G=100\left(G_{C} / G_{F}\right)$

and

$\mathrm{RG}=100\left(G_{\mathrm{R}} / G_{F}\right)$

where $G_{R}$ is the number of seeds germinated after being transferred from light treatments to dark conditions, $G_{F}$ the number of non-germinated seeds when the transferral was done, $G_{C}$ being the equivalent to $G_{R}$ for seeds that continued in the same light treatment, from which true recovery TR was determined by subtracting from RG the mean value of CG (Dias et al., 2015, 2016).

Two sample comparisons were done by exact or approximate two-tailed Student's $t$ tests with comparison-wise type I error rate of 0.05 after checking for homoscedasticity using the two-tailed $F$ distribution with a comparison-wise type I error rate of 0.05 . Whenever comparisons among several means were intended, homoscedasticity was tested as described and if heteroscedasticity was found data was transformed using the Box-Cox family of transformations (Box and Cox, 1964). Lack of "transitivity" is a frequent outcome of multiple comparisons of means (Chew, 1976). Therefore a least squares linear regression approach with dummy variables was adopted to prevent it, and forward stepwise selection with replication was used with candidate models including only light treatments binary coded as $(1,0)$, with an experiment-wise type I error rate of 0.05 for coefficients calculated using Dunn-Šidak method (Ury, 1976). Lack of fit (LOF) was always tested and coefficients of determination $\left(R^{2}\right)$ are presented as proportion of the maximum $R^{2}$ possible (Draper and Smith, 1998). 
Dispersion of data around means was investigated by determining the relative precision of means $\left(D^{\prime}\right)$, which for a given sample of size $n$ can be expressed as:

$D^{\prime}=\left(t^{2} \mathrm{~s}^{2} \overline{\mathrm{Y}}^{-2} / n\right)^{1 / 2}$

where $t$ is the value of Student's $t$ distribution with $n-1$ degrees of freedom and a type I error probability $\alpha$ (set at 0.05), $\mathrm{s}^{2}$ is the variance of the sample with mean $\overline{\mathrm{Y}}$, implying that the larger the value of $D^{\prime}$ the lesser the relative precision of the mean and thus the greater the dispersion of data around the mean (McSorley, 1987; Penas et al., 2002).

Data are presented as mean \pm SE. Linear regressions, nonlinear regressions and ANOVAs were performed using Statgraphics Plus ver. 3.3 (Manugistics, Rockville, USA); determination of Box-Cox transformations using BIOM (Applied Biostatistics, New York, USA); all other statistical analyses using Microsoft Excel $^{\circledR} 2010$.

\section{RESULTS}

No significant equation could be fitted to describe the relationship between seed mass and final germination, lag of germination $(D)$, duration of germination $\left(D_{100}\right)$, or shape of germination $(c)$.

\section{Dry seeds experiment}

Among seeds that failed to germinate in the end of the experiment 4\% were visibly decaying, dead seeds, the remaining being almost without exception hard seeds which visibly had not imbibed.

Germination data are presented at Table 1. Final germination $\left(G_{F}\right)$ ranged from $82.0 \pm 3.8 \%$ in white light treatment to $90.0 \pm 1.2 \%$ in blue light treatment. Significant differences were found between white light treatment and all other treatments which did not significantly differ among them (coefficients with $P \leq 0.02 ; R^{2}=0.952 ; F_{\mathrm{LOF} \cdot 2,12}=0.164$, $P=0.85)$. Pooled $G_{F}$-value for dark, red and blue light treatments was $89.0 \pm 0.9 \%$.
A graphic analysis of cumulative germination provided little or no evidences for a bi- or multimodal distribution of germination over time (not shown). Significant Weibull equations could always be fitted to data except in one replicate of the white light treatment. $R^{2}$ ranged from 0.288 to 0.963 , with a mean value of $0.687 \pm 0.064$ and a median of 0.843 . Lag of germination ( $)$ almost didn't vary among treatments and no significant differences were found among $l$-values.

Duration of germination $\left(D_{100}\right)$ ranged from $5.35 \pm 1.04$ days in red light treatment to $8.16 \pm 1.68$ days in dark treatment. Heteroscedasticity was found among samples and analysis of $D_{100}$ was performed after Box-Cox transformation of data $(\lambda=-0.35038)$. Significant differences were found between red light treatment and all other treatments which did not significantly differ among them (coefficients with $\left.P \leq 0.01 ; R^{2}>0.999 ; F_{\mathrm{LOF} ; 2,11}=1.932 \times 10^{-5}, P \approx 1\right)$. Pooled $D_{100}$-value for dark, blue and white light treatments was $7.9 \pm 0.6$ days.

Shape of germination $(c)$ ranged from $1.34 \pm 0.16$ in dark treatment to $3.24 \pm 0.99$ in blue light treatment. Heteroscedasticity was also found among samples and analysis of $c$ was performed after Box-Cox transformation of data $(\lambda=-1.00458)$. Significant differences were found between blue light treatment and all other treatments which did not significantly differ among them (coefficients with $\left.P \leq 0.02 ; R^{2}=0.718 ; F_{\mathrm{LOF} ; 2,11}=1.466, P=0.27\right)$. Pooled $c$-value for dark, red and white light treatments was $1.63 \pm 0.17$.

Relative precision of means (D') ranged from 1.26 (least precise) to 0.040 (more precise). Duration of germination $\left(D_{100}\right)$ apart, white light treatment was always associated to least precise means, thus with more variable responses, and dark treatment was always associated to the second more precise means, thus with less variable responses, and no clear pattern emerged in relation to red or blue light treatments.

\section{Imbibed seeds experiment}

Among seeds that failed to germinate in the end of the experiment 3\% were visibly decaying, dead seeds, and

Table 1: Means \pm SE of germination parameters of seeds of subterranean clover 'Seaton Park' treated when dry with constant dark or with constant red, blue or white light and incubated in constant dark (dry seeds experiment). Inside parentheses values of relative precision of means

\begin{tabular}{lcccc}
\hline Light treatments $^{\mathrm{a}}$ & \multicolumn{4}{c}{ Germination parameters } \\
\cline { 2 - 5 } & $\begin{array}{c}\text { Final } \\
\text { germination }(\%)\end{array}$ & $\begin{array}{c}\text { Lag of germination } \\
\text { (days) }\end{array}$ & $\begin{array}{c}\text { Duration of } \\
\text { germination (days) }\end{array}$ & $\begin{array}{c}\text { Shape of } \\
\text { germination }\end{array}$ \\
\hline Dark & $88.1 \pm 1.7(0.061)$ & $0.5813 \pm 0.0096(0.052)$ & $8.16 \pm 1.68(0.65)$ & $1.34 \pm 0.16(0.37)$ \\
Red & $89.0 \pm 1.9(0.068)$ & $0.5834 \pm 0.0074(0.040)$ & $5.35 \pm 1.04^{\mathrm{b}}(0.62)$ & $1.64 \pm 0.04(0.08)$ \\
Blue & $90.0 \pm 1.2(0.041)$ & $0.5793 \pm 0.0190(0.104)$ & $7.64 \pm 0.35(0.15)$ & $3.24 \pm 0.99^{\mathrm{b}}(0.97)$ \\
White & $82.0 \pm 3.8^{\mathrm{b}}(0.149)$ & $0.5860 \pm 0.0337(0.247)$ & $7.77 \pm 1.00(0.54)$ & $2.00 \pm 0.59(1.26)$ \\
\hline
\end{tabular}

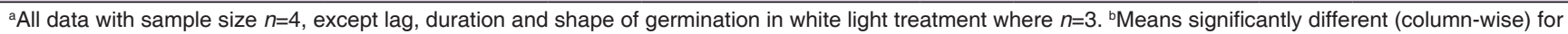
an experiment-wise error rate of 0.05 
slightly more than a third of the remaining were clearly hard seeds which visibly had not imbibed. The remaining, all in blue and white light treatments clearly imbibed but failed to germinate and are considered as embryo-dormant (Evans and Smith, 1999).

Final germination data are presented at Table 2. On the $7^{\text {th }}$ DAS, when Petri dishes were divided into continuance and recovery groups germination $\left(G_{F}\right)$ ranged from $6 \pm 3 \%$ in blue light treatment to $82 \pm 5 \%$ in dark treatment. Significant differences were found between blue and white light treatment and between each of them and all other treatments which did not significantly differ between them (coefficients with $\left.P<10^{-3} ; R^{2}=0.997 ; F_{\mathrm{LOF} ; 1,12}=0.978, P=0.34\right)$. Pooled $G_{F}$-value for dark and red light treatments was $80 \pm 3 \%$.

$G_{F}$ at the end of the experiment in the continuance group 19 DAS ranged from $10 \pm 6 \%$ in blue light treatment to $85 \pm 6 \%$ in dark treatment. Significant differences were found between blue and white light treatment and between each of them and all other treatments which did not significantly differ between them (coefficients with $P \leq 10^{-3}$; $\left.R^{2}=0.996 ; F_{\text {LOF; } 1,6}=0.390, P=0.56\right)$. Pooled $G_{F}$-value for dark and red light treatments was $83 \pm 4 \%$.

$G_{F}$ at the end of the experiment in the recovery group 19 DAS ranged from $64.0 \pm 8.0 \%$ in blue light treatment to $88.0 \pm 4.0 \%$ in red light treatment. Significant differences were found between blue light treatment and all other treatments which did not significantly differ among them (coefficients with $P \leq 0.02 ; R^{2}=0.984 ; F_{\mathrm{LOF} ; 2,6}=0.051$,
$P=0.95)$. Pooled $G_{F}$-value for dark, red and white light treatments was $86.0 \pm 3.4 \%$.

Continuance of germination (CG) ranged from 3.3 $3.3 \%$ in white light treatment to $18.3 \pm 10.7 \%$ in dark treatment. Significant differences were found between dark treatment and all other treatments which did not significantly differ among them (coefficients with $P=0.03 ; R^{2}=0.838$; $\left.F_{\mathrm{LOF} ; 2,7}=0.559, P=0.60\right)$. Pooled CG-value for red, blue and white light treatments was $5.9 \pm 3.2 \%$.

Because in the dark treatment seeds were always incubated under dark, recovery of germination (RG) was only determined for red, blue and white light treatments, ranging from $51.4 \pm 8.6 \%$ in the former to $74.0 \pm 20.1 \%$ in the latter and no significant differences were found among recovery of germination of seeds that were treated with red, blue or white light.

A graphic analysis of cumulative germination in continuance seeds provided little or no evidences for a bi- or multimodal distribution of germination over time (not shown). Significant Weibull equations could always be fitted to data except in replicates of blue light treatment in which germination was too low to make it possible or meaningful. $R^{2}$ ranged from 0.810 to 0.911 , with a mean value of $0.860 \pm 0.011$ and a median of 0.861 . Data of fitted Weibull equations are presented at Table 3. Lag of germination ( $/$ ranged from $0.259 \pm 0.015$ days in white light treatment to $0.332 \pm 0.010$ in the dark treatment. Significant differences were found between white light treatment and

Table 2: Means \pm SE of germination, continuance of germination and recovery of germination of imbibed seeds of subterranean clover 'Seaton Park' treated with constant dark or with constant red, blue or white light during 7 days, 19 days in continuance seeds or 7 days plus 12 days in dark conditions in recovery seeds (imbibed seeds experiment). Inside parentheses values of relative precision of means

\begin{tabular}{|c|c|c|c|c|c|}
\hline \multirow{2}{*}{$\begin{array}{l}\text { Light } \\
\text { treatments }^{a}\end{array}$} & \multicolumn{3}{|c|}{ Final germination (\%) } & \multirow{2}{*}{$\begin{array}{l}\text { Continuance of } \\
\text { germination }(\%)\end{array}$} & \multirow{2}{*}{$\begin{array}{c}\text { Recovery of } \\
\text { germination (\%) }\end{array}$} \\
\hline & (7 days, constant) & $\begin{array}{l}\text { (19 days, } \\
\text { constant) }\end{array}$ & $\begin{array}{l}\text { (7 days, constant } \\
+12 \text { days dark) }\end{array}$ & & \\
\hline Dark & $82 \pm 5(0.20)$ & $85 \pm 6(0.2)$ & $84.9 \pm 5.7(0.21)$ & $18.3 \pm 10.7^{b}(1.9)$ & - \\
\hline Red & $77 \pm 2(0.08)$ & $80 \pm 4(0.6)$ & $88.0 \pm 4.0(0.58)$ & $10.0 \pm 10.0(12.7)$ & $51.4 \pm 8.6(2.12)$ \\
\hline Blue & $6 \pm 3^{b}(1.37)$ & $10 \pm 6^{b}(7.6)$ & $64.0 \pm 8.0^{b}(1.59)$ & $4.4 \pm 4.3(12.7)$ & $61.0 \pm 11.0(2.29)$ \\
\hline White & $41 \pm 3^{c}(0.27)$ & $44 \pm 0^{c}(0.0)$ & $86.0 \pm 10.0(1.48)$ & $3.3 \pm 3.3(12.7)$ & $74.0 \pm 20.1(3.46)$ \\
\hline
\end{tabular}

${ }^{a}$ All data with sample size $n=2$, except final germination (7 days constant) and dark treatment where $n=4$. ${ }^{\mathrm{b}, \mathrm{c}}$ Means significantly different (column-wise) for an experiment-wise error rate of 0.05

Table 3: Means \pm SE of Weibull parameters of imbibed seeds of subterranean clover 'Seaton Park' treated with constant dark or with red or white light during 19 days, continuance seeds (imbibed seeds experiment). Inside parentheses values of relative precision of means

\begin{tabular}{lccc}
\hline Light treatments $^{\mathrm{a}}$ & $\begin{array}{c}\text { Lag of germination } \\
\text { (days) }\end{array}$ & $\begin{array}{c}\text { Duration of germination } \\
\text { (days) }\end{array}$ & $\begin{array}{c}\text { Shape of } \\
\text { germination }\end{array}$ \\
\hline Dark & $0.332 \pm 0.010(0.09)$ & $5.4 \pm 1.5(0.9)$ & $1.30 \pm 0.34(0.8)$ \\
Red & $0.326 \pm 0.002(0.09)$ & $4.1 \pm 2.5(7.9)$ & $1.59 \pm 0.64(5.1)$ \\
White & $0.259 \pm 0.015^{\mathrm{b}}(0.76)$ & $7.7 \pm 6.3(10.4)$ & $3.46 \pm 2.57(9.4)$ \\
\hline
\end{tabular}

Weibull equations were not fitted to blue light treatment because of the very low values of germination it presented. ${ }^{a} \mathrm{All}$ data with sample size $n=2$, except in dark treatment where $n=4$. ${ }^{b}$ Means significantly different (column-wise) for an experiment-wise error rate of 0.05 
all other treatments which did not significantly differ among them (coefficients with $P \leq 0.002 ; R^{2}=0.992 ; F_{\text {LOF }: 1,5}=0.184$, $P=0.69)$. Pooled $l$-value for dark and red light treatments was $0.330 \pm 0.006$ days.

Duration of germination $\left(D_{100}\right)$ ranged from $4.1 \pm 2.5$ days in red light treatment to $7.7 \pm 6.3$ days in white light treatment but probably due to the large variability of the latter no significant differences were found among $D_{100}$-values. Shape of germination (c) ranged from $1.30 \pm 0.34$ in dark treatment to $3.46 \pm 2.57$ in white light treatment. Heteroscedasticity was found among samples and analysis of $c$ was performed after Box-Cox transformation of data $(\lambda=-1.46398)$ but again probably due to the large variability of the white light treatment no significant differences were found among $c$-values.

Because in the dark treatment the concept of recovery does not apply and because in the red light treatment the number of germinated seeds in the recovery group was too low to make it possible or meaningful, Weibull equations were fitted only to recovery data of blue and white light treatments. Significant Weibull equations could always be fitted to data, $R^{2}$ ranged from 0.762 to 0.941 , with a mean value of $0.867 \pm 0.039$ and a median of 0.882 .

Lag of germination $l$ in recovery seeds treated with white light was $1.23 \pm 0.74$ days, not significantly different from $l$ in recovery seeds treated with blue light $(1.66 \pm 0.85$ days; $\left.t_{2}=0.380, P=0.74\right)$ or from $l$ in continuance seeds treated during 19 days with white light $\left(t_{2}=1.019, P=0.415\right)$. Duration of germination $\left(D_{100}\right)$ in recovery seeds treated with white light was $4.8 \pm 0.6$ days, not significantly different from $D_{100}$ in recovery seeds treated with blue light $\left(7.3 \pm 1.2\right.$ days; $\left.t_{2}=1.760, P=0.22\right)$ or from $D_{100}$ in continuance seeds treated 19 days with white light $\left(t_{2}=0.447, P=0.70\right)$. The same happened with shape of germination $(c)$ in recovery seeds treated with white light which was $2.50 \pm 0.62$, not significantly different from $c$ in recovery seeds treated with blue light $\left(2.61 \pm 0.84 ; t_{2}=0.099\right.$, $P=0.93)$ or from $c$ in continuance seeds treated 19 days with white light $\left(t_{2}=0.364, P=0.75\right)$.

Relative precision of means ( $\left.D^{\prime}\right)$ ranged from 12.7 (least precise) to 0 (maximum precision possible). Final germination of continuance seeds apart, white light treatment was always associated to the least or to the second least precise means, thus with more variable responses, closely followed by blue light treatments when data was available. Conversely dark treatment was always associated to the more or to the second more precise means, thus with less variable responses, and no clear pattern emerged in relation to red light treatment (Tables 2 and 3).

\section{Comparison between dry and imbibed seeds experiments}

Significant differences between light treatments done on dry and on imbibed seeds were found in final germination of seeds treated with blue and white light treatments (Fig. 2a), and in lag of germination of seeds treated with dark or with red or white light (Fig. 2b). Whenever significant differences were found, observed values of germination and lag of germination were larger in treatments done to dry seeds than in their counterparts done to imbibed seeds. Conversely no significant differences between experiments were found either in duration or in shape of germination (Fig. 2c and d).

\section{DISCUSSION}

Data of final germination, of lag of germination, of duration of germination, and of shape of germination could not be explained by differences of mass among seeds, which means that the responses to dark or to light conditions were essentially independent of mass and should be attributed to dark or light.

\section{Comparison between dry and imbibed seeds experiments}

The dark treatment was essentially the same in the two experiments and therefore it is not surprising the lack of significant differences in germination, duration of germination and shape of germination between dry and imbibed seeds treated. However and somehow surprisingly, significant differences were found in lag of germination and thereby the time needed for the first seed to germinate was greater in dry seeds experiment than in imbibed seeds experiment. A similar pattern of significant differences between the two experiments is found in seeds treated with red light but only in lag of germination. Nevertheless in the two experiments, regardless of light treatment seeds began germinating in less than an estimated 14 hours from the start of imbibition, which qualifies 'Seaton Park' as a very fast germinating cultivar (Parsons, 2012).

Very fast germination (VFG) is related to high stress habitats, namely to arid, saline and flooded habitats. Species with this trait, which evolved independently many times during angiosperm evolution, frequently have small to very small seeds with little or no endosperm or perisperm and thin membranous seed coats that imbibe rapidly (Parsons, 2012; Parsons et al., 2014). However 'Seaton Park' only partially fits in these characteristics. 'Seaton Park', and subterranean clover in general, is not found in high stress habitats as those mentioned, seeds hardly qualify as very small, and at maturation they show an intermediate level of hardseededness (Taylor, 1981; Smetham, 1999; Nichols 


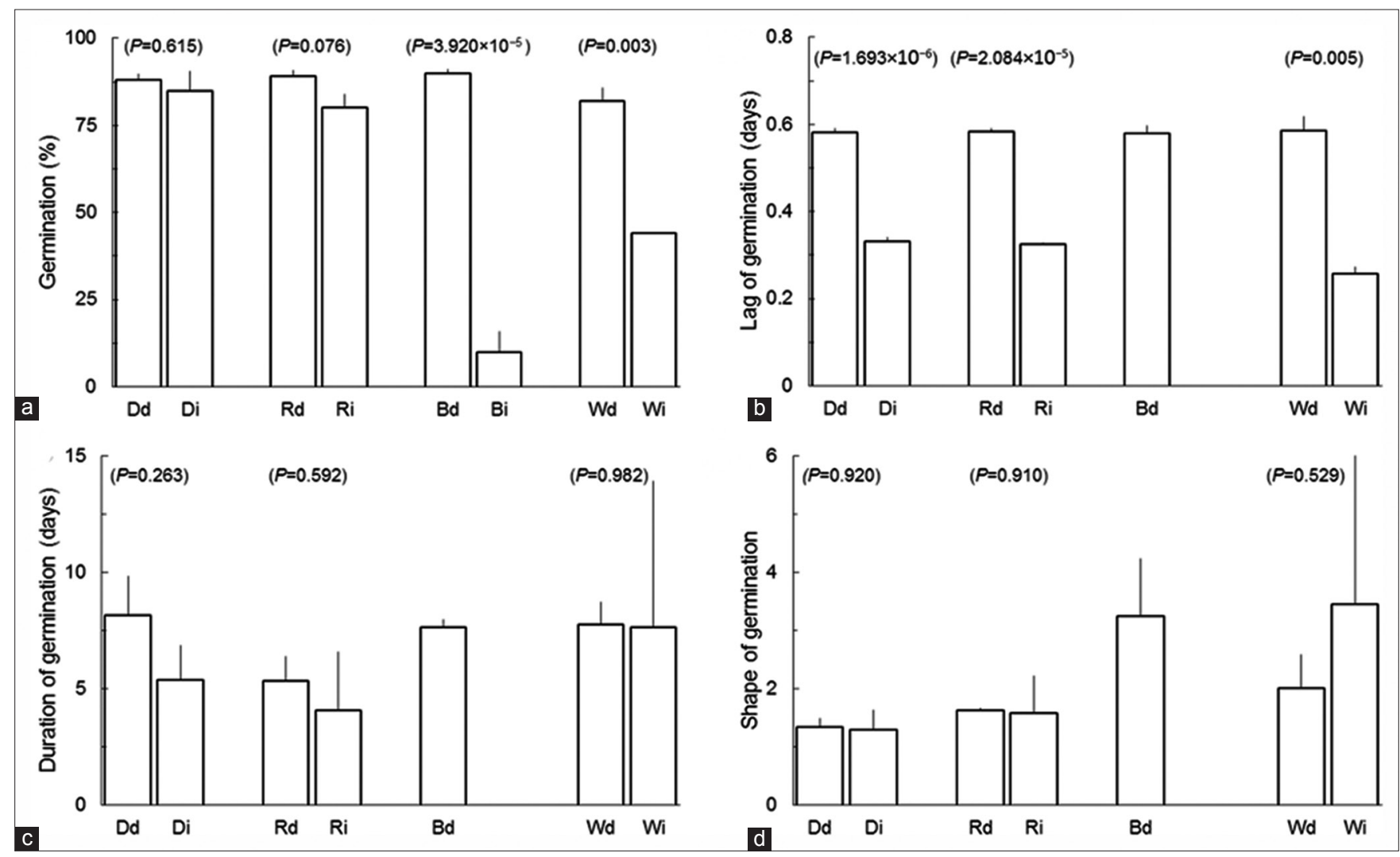

Fig 2. Effects of constant dark (D), or of red (R), blue (B) or white (W) light treatments done to dry (d) or imbibed (i) seeds of subterranean clover 'Seaton Park' on a) germination, b) lag of germination, c) duration of germination, and d) shape of germination of seeds of subterranean clover 'Seaton Park'. Weibull equations were not fitted to imbibed seeds treated with blue light. Data expressed as mean+SE. Inside parentheses significant levels $(P)$ for exact or approximate two-tailed Student's $t$ tests with a comparison-wise type I error rate of 0.05 between treatments done to dry and imbibed seeds.

et al., 2013). Conversely, like in other Trifolium, the embryo occupies almost all seed, the endosperm being almost completely absent (Martin, 1946).

In addition, VFG in 'Seaton Park' was essentially insensitive to the whole range of light treatments and because of its response to dark treatments, also essentially insensitive to the order in which treatments are done, VFG occurring in seeds treated either when dry or when imbibed.

However, when imbibed seeds that failed to germinate under blue or white light were transferred to dark conditions (recovery seeds), VFG was lost and lag of germination more than triples to $\sim 40$ hours counted from the time of transferral in seeds previously incubated under blue light, slightly less in those previously under white light ( 30 hours).

\section{Dry seeds experiment}

Goggin and Steadman (2012) remarked the lack of knowledge on the action of blue light receptors in dry seeds and this experiment was essentially designed to evaluate the effects on germination of light treatments imposed to dry seeds which were subsequently imbibed and incubated in dark conditions, thus contributing to reduce such lack of knowledge.

Final germination did not differ between dry seeds treated with dark and with red light which clearly indicates that phytochromes played no part in the process (Gubler et al., 2008). It has been shown that red light is very inefficiently perceived by dry seeds. In such seeds the inactive phytochrome $\mathrm{P}_{\mathrm{r}}$ irradiated with red light originates lumi-R, the first intermediate in $\mathrm{P}_{\mathrm{r}} \rightarrow \mathrm{P}_{\mathrm{fr}}$ pathway, and rapidly reverts to its initial form (Bartley and Frankland, 1984). A good chance exists that in dry seeds, like in other dry tissues, phytochrome A (phyA) occurs essentially in the form phyA" incapable of transitioning to lumi-R (Sineshchekov, 2006). Thus phytochromes would absolutely require water to effective functioning. Baskin and Baskin (2000) abstracted data on water content of seeds making clear that water was in remarkably low amount in the 'Seaton Park' seeds used in this experiment (6.3\% or less). Altogether this implies that phytochromes play no part in the response of seeds irradiated by red light. The absence of effects in seeds pre-treated with blue light supports the conclusion that similar lack of effects happens with the blue light receptors chryptochrome and phototropin 
(Goggin and Steadman, 2012). The only treatment that affected final germination of 'Seaton Park' seeds, reducing it, was white light, which implies a negative photoblastic response of seeds. Because the white light used comprises in descending order of magnitude, green, red and blue light, the two latter being ineffective as shown above, the activity of some green light receptor would be required to explain the inhibition of germination by white light.

Enhancing effects by green light are known to counter reducing effects of blue light on seed germination (Bouly et al., 2007; Banerjee et al., 2007). However, the putative effects of green light found here are inhibitory instead of stimulatory as is usually the case with green light, because no effects were found associated with blue light, which are usually inhibitory. Exceptions to stimulatory effects of green light exist but are rare. The only case we found involved short exposures to green light of seeds of Chondrilla juncea incubated under dark that increased its final germination (Luna et al., 2004). However in that study green light was provided to imbibed seeds, not to dry seeds as we did. In addition wetted seeds were stratified at $5{ }^{\circ} \mathrm{C}$ during four weeks before being incubated, a procedure also not followed in our experiment. In all likelihood the very low fluency-response to green light observed in C. juncea and other species investigated by those authors only happened because of pre-conditioning of seeds at low temperatures (Pons, 2014).

More puzzling are the effects on duration and shape of germination of dry seeds. In the first parameter, pre-treatment of dry seeds with red light significantly reduced the time elapsed from the germination of the first to the germination of the last seed. Such reduction could represent an advantage by concentrating in time the emergence and early growth of seedlings and plantlets. In the second, the value of shape of germination (c) of seeds pre-treated with blue light is almost within the range of $c$-values for which the distribution of germination over time is symmetric while in all other treatments $c$-values show the positive asymmetry of germination over time usually found in subterranean clover seeds (Dias, 2001; Dias and Moreira, 2002). Thus, the way seed germination of 'Seaton Park' evolves after imbibition is changed by blue light imposed to dry seeds. Because of the low values of $c$, probably only a small number of factors, acting multiplicatively, usually govern 'Seaton Park' seed germination but blue light somehow changes the underlying processes, the result being not only the possible increase in the number of factors but also and more important, effects became additive, a requisite to symmetry to be found (Limpert et al., 2001).

Therefore and whichever those factors are and whatever the way duration of germination is reduced, blue light and red light photoreceptors must be operating. Simultaneously their inactivity is implied by the results of final germination, two clearly contradictory conclusions. An alternative, hypothetical explanation requiring testing is that red and blue light are operating in dry seeds not only on duration and shape of germination but also on final germination. When seeds are subsequently transferred to dark and allowed to imbibe, effects on final germination mediated by photoreceptors would be completely reversed in the case of seeds treated when dry with monochromatic red or blue light, only partially reversed in the case of white light pre-treatments.

Interestingly, the behaviour of seeds treated with white light when they were dry is much more heterogeneous that in all other treatments, as shown by the lower precision of seed responses, similar to what was found when imbibed seeds were treated with dark or with red, blue or white light. This reduced stability or increased plasticity of germination response under white light may widen the range of responses when seeds are in less than optimal conditions (Schlichting, 1986). However and somehow surprisingly, dark treated seeds immediately follow in the rank of lower precision.

\section{Imbibed seeds experiment}

Undoubtedly a more clear and coherent picture emerges from this experiment which was designed to evaluate the effects of constant dark or of constant light treatments during imbibition and incubation on germination of 'Seaton Park' seeds. Final germination of seeds continuously kept under dark or light treatments was drastically reduced by blue and white light while no significant differences were found between dark and red light treatments. This is typically a negative photoblastic response and the installation of this pattern was very fast. Inhibition of germination being evident at 16 hours after sowing in blue light treatment and slightly later at 24 hours in white light treatment, while responses to dark and to red light were almost undistinguishable throughout the experiment.

Like in the dry seeds experiment, lack of differences between the germination of seeds incubated in dark and under red light implies that phytochromes are playing no part. Conversely the inhibition by blue light implies that cryptochromes or phototropins are playing a role. Absence of red light involvement together with inhibition of seed germination by blue light has also been reported in wheat and barley, species that like subterranean clover have been domesticated, and for a much longer period, while in the non-domesticated grass Brachypodium distachyon final germination was found to be strongly enhanced by red light (Barrero et al., 2012, 2014). 
Not only significant effects on final germination were found only in blue and white light treatments but also significant differences were found between blue and white light effects, with blue reducing germination more than white, in agreement with known combined effects of blue and green light. Briefly, exposition to blue light partially reduces oxidized flavin adenine dinucleotide (FAD) to a stable semiquinone radical intermediate, which is the active state of cryptochrome's chromophore. Irradiance with green light completely reduces the semiquinone, totally inactivating it (Bouly et al., 2007; Banerjee et al., 2007). As could be expected from the mechanism of blue and green light effects just described, the value of shape of germination in imbibed seeds treated with white light reveals a symmetric distribution and a clear sign of additivity of factors controlling germination (Limpert et al., 2001) In addition it is worth remarking that the ratio between final germination under constant blue and white light in the end of the experiment (0.23) almost exactly mirrors the proportion of blue in the white light used (0.21), providing further support for the conclusion that observed effects on final germination of 'Seaton Park' seeds are under control of cryptochromes, and in all likelihood without participation of phototropins because responses to green light, as those observed here, seem to be absent from phototropins (Goggin and Steadman, 2012).

The recognition of a negative photoblastic response of imbibed seeds of subterranean clover 'Seat Park' and its mediation by cryptochromes lead to the question of what would happen if seeds that failed to germinate in blue or white light treatments were changed to a dark environment and allowed to germinate. In other words, are the inhibitory effects of blue light permanent or transient?

The response is that effects are completely transient with full recovery in seeds that had been incubated under white light and only partial in seeds that had been incubated under monochromatic blue light. The mechanism for germination recovery would involve the re-oxidation of FAD that was partially or completely reduced when seeds were irradiated with blue light alone or with blue and green light, returning to a form that can be again made active if blue light comes again to the scene (Banerjee et al., 2007).

However, large recovery values like those observed after blue and white light treatments could also result just from more time having been allowed to seed germination and not represent a true recovery of germination resulting from the removal of the inhibitory factor(s), in this case the removal of blue light and transferral to dark (Dias et al., 2015, 2016). Therefore the need to determine the effect of more time to germinate, provided by continuance groups. In this study more time alone would clearly have a negligible effect on the recovery of seeds that failed to germinate under blue and white light. Thus the large recovery observed can be equated to true recovery. Despite that seeds had already imbibed, lag of germination after transferral to dark conditions drastically increased in recovery seeds as remarked above, implying that the reversal of blue light effects through the re-oxidation of FAD is not a fast process. Duration of germination is also increased, more than doubling in seeds treated with monochromatic blue light. The overall result was that germination of bluetreated seeds had not yet fully recovered 12 days after transferral to dark, while fully recovery of white-treated seeds was found 7 days after their transferral to dark. This result agrees with the lower amount of the active semiquinone radical intermediate that should result from the effect of green light present in white light, but implies that non-germinated seeds recovering from irradiance by monochromatic blue light were not embryo-dormant as they have been stated that they would be (Evans and Smith, 1999).

In short, subterranean clover 'Seaton Park' is a negative photoblastic cultivar in which germination is essentially controlled by blue light mediated by cryptochromes, with the ratio blue/green light seemingly determinant of the ability of seeds to germinate.

Bond et al. (1999) presented an equation to estimate the maximum depth for successful emergence of seedlings from seeds mass. Thus the maximum depth for emergence of 'Seaton Park' seedlings in soil would be in the range 38.0-64.5 mm. Bliss and Smith (1985) showed that shorter wavelengths rapidly disappear as depth increases, with blue light totally absent at $6 \mathrm{~mm}$-depth and green light at $9 \mathrm{~mm}$ in coarse sand with few if any differences between dry and moist sand. The same in 1-2 $\mathrm{mm}$ diameter clay-loam aggregates. Therefore burr burial, even at shallow depths and far from maximum depth for successful emergence of seedlings, will place seeds in sites were blue light and consequently germination inhibition mediated by light is totally absent, signalling seeds that their location might be optimal for germination.

In general seed burial may be advantageous by a number of reasons including the reduction or prevention of herbivory or of seed removal by surface-foraging predators (Crawley, 2000). Chapman and Asseng (2001) showed that subterranean clover is particularly prone to mortality in false breaks that result from wetting-desiccation cycles. Because such cycles are more intensely suffered at soil surface than below-ground, burial can help in escaping their effects. However, subterranean clover gets an additional benefit from seed burial because the top-down resistance imposed to buried seeds by soil facilitates radicle 
penetration. Conversely elongating radicles of seeds germinated at soil surface hardly penetrate it but instead push seeds away from the soil surface eventually leading to seedling death (Dowling et al., 1971).

Unburied seeds, which might occur if seeds are sown and not buried, would be in an environment enriched in blue light but also with abundant green light. Germination would occur but at much smaller level than in buried seeds, thus balancing the higher risks of surface germination and increasing the size of the seed bank. Additionally, the behaviour of seeds would be much more heterogeneous as evidenced by the much low precision of seed responses to white light in comparison to their responses to light treatments, which potentially widens the range of possible responses to less than optimal conditions.

\section{ACKNOWLEDGEMENTS}

The authors thank Fertiprado Lda. for subterranean clover seeds, Augusto Peixe for all support during this study, and Hugo Ribeiro for the help in determinations of spectral photon distributions. The study was done in the framework of a contract between Universidade de Évora and Aralab, Lda. (Contract No. 4872) entitled "Incorporação da Iluminação LED em Câmaras Climáticas para a Cultura de Espécies Vegetais em Ambiente Controlado" ("Incorporation of LED Illumination in Climatic Chambers Designed for Growth of Plants in Controlled Conditions").

\section{Author's contribution}

$A C$ and ASD designed, set up and executed the experiment, collected germination data, interpreted the results and wrote the manuscript. MGG determined mass and linear dimensions of seeds. LSD collaborated in experimental design and in data collection, performed statistical analyses, interpreted the results and wrote the manuscript which was read and approved by all authors.

\section{REFERENCES}

Bakker, J. P., P. Poschlod, R. J. Strykstra, R. M. Bekker and K. Thompson. 1996. Seed banks and seed dispersal: Important topics in restoration ecology. Acta Bot. Neerl. 45: 461-490.

Banerjee, R., E. Schleicher, S. Meier, R. M. Viana, R. Pokorny, M. Ahmad, R. Bittl and A. Batschauer. 2007. The signaling state of Arabidopsis cryptochrome 2 contains flavin semiquinone. J. Biol. Chem. 282: 14916-14922.

Barrero, J. M., A. B. Downie, Q. Xu and F. Gubler. 2014. A role for barley CRYPTOCHROME1 in light regulation of grain dormancy and germination. Plant Cell. 26: 1094-1104.

Barrero, J. M., J. V. Jacobsen, M. J. Talbot, R. G. White, S. M. Swain, D. F. Garvin and F. Gubler. 2012. Grain dormancy and light quality effects on germination in the model grass Brachypodium distachyon. New Phytol. 193: 376-386.

Bartley, M. R. and B. Frankland. 1984. Phytochrome intermediates and action spectra for light perception by dry seeds. Plant Physiol. 74: 601-604.

Baskin, C. C. and J. M. Baskin. 2000. Seeds. Ecology, Biogeography and Evolution of Dormancy and Germination, Academic Press, New York.

Bliss, D. and H. Smith. 1985. Penetration of light into soil and its role in the control of seed germination. Plant Soil Environ. 8: 475-483.

Bond, W. J., M. Honig and K. E. Maze. 1999. Seed size and seedling emergence: An allometric relationship and some ecological implications. Oecologia. 120: 132-136.

Bonner, F. T. and T. R. Dell. 1976. The Weibull function: A new method of comparing seed Vigor. J. Seed Technol. 1: 96-103.

Bouly, J.P., E. Schleicher, M. Dionisio-Sese, F. Vandenbussche, D. V. D. Straeten, N. Bakrim, S. Meier, A. Batschauer, P. Galland, R. Bittl and M. Ahmad. 2007. Cryptochrome blue light photoreceptors are activated through interconversion of flavin redox states. J. Biol. Chem. 282: 9383-9391.

Box, G. E. P. and D. R. Cox. 1964. An analysis of transformations. J. R. Stat. Soc. B. 26: 211-252.

Casco, H. and L. S. Dias. 2008. Estimating seed mass and volume from linear dimensions of seeds. Seed Sci. Technol. 36: 230-236.

Chapman, R. and S. Asseng. 2001. An analysis of the frequency and timing of false break events in the Mediterranean region of Western Australia. Aust. J. Agric. Res. 53: 367-376.

Chew, V. 1976. Comparing treatment means: A compendium. HortScience. 11: 348-357.

Crawley, M. J. 2000. Seed predators and plant population dynamics. In: M. Fenner (Ed.), Seeds. The Ecology of Regeneration in Plant Communities, $2^{\text {nd }}$ ed. CABI Publishing, Wallingford, O. X., pp. 167-182.

Dias, L. S. 2001. Describing phytotoxic effects on cumulative germination. J. Chem. Ecol. 27: 411-418.

Dias, L. S. and I. Moreira. 2002. Interaction between water soluble and volatile compounds of Cistus ladanifer L. Chemoecology. 12: $77-82$.

Dias, L. S., A. S. Dias and I. P. Pereira. 2015. Ionic effects of $\mathrm{NaCl}$ counter osmotic inhibition of germination and seedling growth of Scorzonera hispanica and subsequent plantlet growth is not affected by salt. Botany. 93: 485-496.

Dias, L. S., I. P. Pereira and A. S. Dias. 2016. Allelopathy, seed germination, weed control and bioassay methods. Allelop. J. 37: $31-40$

Dowling, P. M., R. J. Clements and J. R. McWilliam. 1971. Establishment and survival of pasture species from seeds sown on the soil surface. Aust. J. Agric. Res. 22: 61-74.

Draper, N. R. and H. Smith. 1998. Applied Regression Analysis, $3^{\text {rd }}$ ed. John Wiley \& Sons, Inc., New York.

Dubey, S. D. 1967. Normal and Weibull distributions. Nav. Res. Logist. Q. 14: 69-79.

Evans, P. M. and F. A. Smith. 1999. Patterns of seed softening in subterranean clover in a cool, temperate environment. Agron. J. 91: 122-127.

Fenner, M. and K. Thompson. 2005. The Ecology of Seeds, Cambridge University Press, Cambridge.

Francis, C. M., B. J. Quinlivan and H. I. Nicol. 1972. Variation in burr burial ability in subterranean clover. Aust. J. Agric. Res. 23: 605-610.

Goggin, D. E. and K. J. Steadman. 2012. Blue and green are frequently seen: Responses of seeds to short-and mid-wavelength light. 
Seed Sci. Res. 22: 27-35.

Górski, T., K. Górska and J. Nowicki. 1977. Germination of seeds of various herbaceous species under leaf canopy. Flora. 166: 249-259.

Górski, T., K. Górska and J. Rybicki. 1978. Studies on the germination of seeds under leaf canopy. Flora. 167: 289-299.

Gubler, F., T. Hughes, P. Waterhouse and J. Jacobsen. 2008. Regulation of dormancy in barley by blue light and after-ripening: Effects on abscisic acid and gibberellin metabolism. Plant Physiol. 147: 886-896.

Howieson, J. G., R. J. Yates, K. J. Foster, D. Real and R. B. Besier. 2008. Prospects for the future use of legumes. In: Dilworth, M. J., E. K. James, J. I. Sprent and W. E. Mewton (Eds.), NitrogenFixing Leguminous Symbioses, Springer Science and Business Media, B. V., Dordrecht, pp. 363-393.

Kitajima, K. and M. Fenner. 2000. Ecology of seedling regeneration. In: M. Fenner, (Ed.), Seeds. The Ecology of Regeneration in Plant Communities. $2^{\text {nd }}$ ed. CABI Publishing, Wallingford, pp. 331-359.

Limpert, E., W. A. Staheland and M. Abbt. 2001. Log-normal distributions across the sciences: Keys and clues. BioScience. 51: 341-352.

Luna, B., B. Pérez, F. Fernández-González and J. M. Moreno. 2004. Sensitivity to green safelight of 12 Mediterranean species. Seed Sci. Technol. 32: 113-117.

Marquardt, D. W. 1963. An algorithm for least-squares estimation of nonlinear parameters. J. Soc. Ind. Appl. Math. 11: 431-441.

Martin, A. C. 1946. The comparative internal morphology of seeds. Am. Midl. Nat. 36: 513-660.

McSorley, R. 1987. Extraction of nematodes and sampling methods. In: Brown, R. H. and B. R. Kerry, (Eds.), Principles and Practices of Nematode Control in Crops, Academic Press Australia, Sidney, pp. 13-47.

Milberg, P., L. Andersson and K. Thompson. 2000. Large-seeded species are less dependent on light for germination than smallseeded ones. Seed Sci. Res. 10: 99-104.

Nichols, P. G. H., K. J. Foster, E. Piano, L. Pecetti, P. Kaur, K.
Ghamkhar and W. J. Collins. 2013. Genetic improvement of subterranean clover (Trifolium subterraneum L.). 1. Germplasm, traits and future prospects. Crop Pasture Sci. 63: 691-725.

Nichols, P. G. H., C. K. Revel, A. W. Humphries, J. H. Howie, E. J. Hall, G. A. Sandral, K. Ghamkhar and C. A. Harris. 2012. Temperate pasture legumes in Australia - Their history, current use, and future prospects. Crop Pasture Sci. 64: 312-346.

Parsons, R. F. 2012. Incidence and ecology of very fast germination. Seed Sci. Res. 22: 161-167.

Parsons, R. F., F. Vandelook and S. B. Janssens. 2014. Very fast germination: Additional records and relationship to embryo size and phylogeny. Seed Sci. Res. 24: 159-163.

Penas, A. C., L. S. Dias and M. M. Mota. 2002. Precision and selection of extraction methods of aphelenchid nematodes from maritime pine wood, Pinus pinaster L. J. Nematol. 34: 62-65.

Pons, T. L. 2014. Light-mediated germination. In: R. S. Gallagher (Ed.), Seeds: The Ecology of Regeneration in Plant Communities, $3^{\text {rd }}$ ed. CABI International, Wallingford, UK, pp. 111-134.

Roberts, H. A. and M. E. Ricketts. 1979. Quantitative relationships between the weed flora after cultivation and the seed population in the soil. Weed Res. 19: 269-275.

Schlichting, C. D. 1986. The evolution of phenotypic plasticity in plants. Annu. Rev. Ecol. Syst. 17: 667-693.

Sineshchekov, V. A. 2006. Extreme dehydration of plant tissues irreversibly converts the major and variable phyA' into the minor and conserved phyA". J. Photochem. Photobiol. B. 85: 85-91.

Smetham, M. L. 1999. The ecology and use of subterranean clover (Trifolium subterraneum $h$.) as a pasture legume. An Australasian perspective. Pastos. 39: 5-63.

Taylor, G. B. 1981. Effect of constant temperature treatments followed by fluctuating temperatures on the softening of hard seeds of Trifolium subterraneum L. Aust. J. Plant Physiol. 8: 547-558.

Ury, H. K. 1976. A comparison of four procedures for multiple comparisons among means (pairwise contrasts) for arbitrary sample sizes. Technometrics. 18: 89-97.

Weibull, W. 1951 A statistical distribution function of wide applicability. J. Appl. Mech. 18: 293-297. 